\title{
Progresso temporal da cercosporiose da beterraba em diferentes genótipos e épocas de semeadura na primavera
}

\author{
Leandro Luiz Marcuzzo ${ }^{1}$, Tatiana da Silva Duarte², José Mauricio Cunha Fernandes ${ }^{3}$, Patrícia Cristina Hilleshein ${ }^{1,4}$, \\ Bruno Tabarelli Scheidt ${ }^{1,4}$
}

${ }^{1}$ Instituto Federal Catarinense - IFC/Campus Rio do Sul, CP 441, CEP 89.163-356, Rio do Sul, SC; ${ }^{2}$ Epagri - Estação Experimental de Ituporanga, CEP 88400-000 Ituporanga, SC, tatianaduarte@epagri.sc.gov.br; ${ }^{3}$ Embrapa Trigo, Rodovia BR 285, km 174, CP 451, Passo Fundo, RS, mauricio.fernades@cnpt.embrapa.br; ${ }^{4}$ Alunos do curso de Agronomia e Bolsista CNPq, projeto REPENSA - Redes Nacionais de Pesquisa em Agrobiodiversidade e Sustentabilidade Agropecuária, patricia-tina@hotmail.com; brunotabarelli@hotmail.com.

Autor para correspondência: Leandro Luiz Marcuzzo (marcuzzo@ifc-riodosul.edu.br)

Data de chegada: 09/10/2013. Aceito para publicação em: 03/11/2014.

$10.1590 / 0100-5405 / 1938$

\section{RESUMO}

Marcuzzo, L.L.; Duarte, T.S.; Fernandes, J.M.C.; Hilleshein, P.C.; Scheidt, B.T. Progresso temporal da cercosporiose da beterraba em diferentes genótipos e épocas de semeadura na primavera. Summa Phytopathologica, v.41, n.3, p.219-223, 2015.

A cultura da beterraba tem se intensificado devido ao consumo in natura e também pelo processamento industrial de conservas. Na região do Alto Vale do Itajaí, SC, grande parte da sua produção vem de agricultores familiares que a usam em sucessão a cultura da cebola, com semeadura na primavera/verão. Entretanto, nesta época do ano a cercosporiose (Cercospora beticola) tem comprometido a produtividade. O objetivo do trabalho foi avaliar o progresso desta doença nos genótipos: All Green, Stays Green, Early Wonder, Cabernet, Boro, Modana e Itapuã e avaliar a severidade em duas épocas de semeadura, na primavera. Os dois ensaios foram conduzidos na Epagri/Estação Experimental de Ituporanga, implantados com 30 dias de diferença entre as semeaduras. O delineamento experimental foi de blocos casualizados com quatro repetições. Para avaliação da severidade da doença foi utilizada uma escala diagramática em dez plantas ao acaso previamente demarcadas. Os dados de severidade foram submetidos à análise de modelos mistos, area abaixo da curva de progresso de doença, taxa de infecção e severidade final. Não houve diferenças no progresso da doença entre os genótipos avaliados nas duas épocas de semeadura de primavera nas condições do Alto Vale do Itajaí, SC.

Palavras-chave: Beta vulgaris, genótipos, epidemiologia, Cercospora beticola.

\section{ABSTRACT}

Marcuzzo, L.L.; Duarte, T.S.; Fernandes, J.M.C.; Hilleshein. P.C.; Scheidt, B.T. Temporal progression of Cercospora leaf spot of beet in different genotypes and sowing periods during the spring. Summa Phytopathologica, v.41, n.3, p.219-223, 2015.

Beet cultivation has intensified due to in natura consumption and industrial processing of canned food. In the region of Alto Vale do Itajaí, Santa Catarina State, Brazil, a large part of beet production comes from small farmers, who grow it after the onion crop, sowing it during the spring/summer. However, in this period of the year, Cercospora leaf spot has been noted to compromise the production. The aim of this study was to evaluate the progression of this disease in the following genotypes: All Green, Stays Green, Early Wonder, Cabernet, Boro, Modana and Itapuã, as well as to evaluate its severity in two sowing periods during the spring. The two assays were carried out at Epagri
Experimental Station in Ituporanga, Santa Catarina State, and established at 30day interval between sowing periods. Experimental design was in randomized blocks with four replicates. To evaluate the disease severity, a diagrammatic scale was used for ten plants at random, which were previously demarcated. Data on severity underwent mixed model analysis, yielding area under the disease progress curve (AUDPC), infection rate and final disease severity. There were no differences in the disease progression between the evaluated genotypes for both spring sowing periods under the conditions of Alto Vale do Itajaí, Santa Satarina State, Brazil.

Additional keywords: Beta vulgaris, genotypes, epidemiology, Cercospora beticola.

O cultivo da beterraba (Beta vulgaris L.) tem ampla distribuição geográfica no Brasil. As regiões de clima temperado ou tropical de altitude, com temperaturas amenas no verão, são as mais recomendadas, pois essa hortaliça possui melhor desenvolvimento entre temperaturas de $10^{\circ} \mathrm{C}$ a $20^{\circ} \mathrm{C}(8)$. Mesmo os genótipos indicados para o plantio durante o ano todo têm melhor produção e qualidade de tubérculos no período de outono/inverno, pois nesta época as condições climáticas são desfavoráveis ao desenvolvimento do fungo Cercospora beticola
Saac, agente etiológico da cercosporiose $(16,21)$.

A beterraba é uma das principais hortaliças cultivadas na região do Alto Vale do Itajaí, em Santa Catariana. Segundo levantamento informal, realizado em 2010, junto aos escritórios locais da Empresa de Pesquisa e Extensão Rural de Santa Catariana (Epagri), nos municípios dessa região, estima-se que há mais de 700 hectares com esta cultura, superados apenas pela cultura da cebola, em área. O período de semeadura é realizado no final da primavera e início 
do verão, em sucessão à cultura da cebola, concentrando-se a sua maioria de novembro a meados de janeiro. A região apresenta um clima subtropical úmido (Cfa), segundo a classificação de Köppen, caracterizada por alta umidade e temperatura do ar. Assim, o cultivo de beterraba no verão se torna mais propício a cercosporiose em relação ao período de inverno $(1,8)$.

$\mathrm{Na}$ cultura, a cercosporiose é a principal doença, por promover a destruição foliar e redução na produção (16). Sua ocorrência generalizada pode representar redução na produtividade de $15 \%$ a $45 \%$, em condições de alta umidade relativa do ar, maior que $90 \%$, e temperatura entre 22 e $26^{\circ} \mathrm{C}$ (21). Os sintomas são manchas circulares com bordos de cor purpúrea e centro claro e, à medida que aumentam, tornam-se com tonalidade acinzentada, porém com a necrose o tecido lesionado cai e a folha torna-se perfurada $(9,10)$. O aumento do número de lesões e o aumento da área, juntamente com o acúmulo de fitotoxinas, induzem à completa senescência da folha e uma redução significativa da área foliar, e sua conseqüente produção. As folhas mais velhas são mais suscetíveis ao desenvolvimento da doença (23).

Para o conhecimento do desenvolvimento das doenças, a análise temporal tem sido a mais utilizada. A análise temporal de doenças, a análise da curva de progresso de uma epidemia e a interpretação do formato dessas curvas é fundamental para distinguir variedades e comparar os danos causados pela doença (12).

Modelos não lineares, comumente usados para representar crescimento de epidemias como o Logístico e o de Gompertz, podem se comportar de forma diferente conforme a repetição, tratamento e unidade experimental. Mediante a isso, os dados observados numa mesma unidade experimental ao longo do tempo são modelados mais adequadamente por modelos de efeitos mistos. Pois nesses casos, a análise de variância clássica leva à violação da independência entre as observações que esta técnica pressupõe. Por outro lado, os modelos não lineares de efeitos mistos permitem explorar e modelar adequadamente o progresso de uma epidemia (5).

A pouca literatura existente a respeito do progresso da cercosporiose é sobre beterraba açucareira e produzida na Europa $(2,10)$. Entretanto, esta apresenta ciclo e genótipos diferentes das beterrabas utilizadas para o consumo no Brasil. Assim, este trabalho teve como objetivo analisar o progresso da cercosporiose em diferentes genótipos e avaliar qual a época de semeadura na primavera mais propicia a ocorrência da doença, nas condições climáticas do Alto Vale do Itajaí/SC.

\section{MATERIAL E MÉTODOS}

Dois experimentos foram conduzidos durante o período de novembro de 2012 a fevereiro de 2013, na Epagri/Estação Experimental de Ituporanga, localizada no município de Ituporanga, SC, região do Alto Vale do Itajaí. As coordenadas geográficas são de latitude de $27^{\circ} 38^{\prime} \mathrm{S}$, longitude de $49^{\circ} 60^{\prime} \mathrm{W}$ e altitude de 475 metros acima do nível do mar. Segundo a classificação de Köeppen, o clima local é do tipo Cfa e o solo é classificado como Cambissolo Háplico Tb distrófico (7).

Os experimentos foram implantados sucessivos, com 30 dias de diferença, semeados em 31 de outubro e 30 de novembro de 2012. Utilizaram-se sete diferentes genótipos de beterraba, os mais utilizados pelos agricultores na região, para avaliação da resistência a cercosporiose: All Green, Stays Green, Early Wonder Tall Top, Cabernet (híbrido), Boro (híbrido), Modana (monogérmica) e Itapuã. $\mathrm{O}$ delineamento experimental foi em blocos casualizados com quatro repetições. Os dois experimentos foram separados por um espaço de
3 metros. A semeadura foi realizada manualmente, sendo que cada unidade experimental continha $2,25 \mathrm{~m}^{2}(1,5 \mathrm{~m} \times 1,5 \mathrm{~m})$, dividida em 5 linhas com espaçamento de $30 \mathrm{~cm}$ entre linhas e $10 \mathrm{~cm}$ entre plantas, contendo um total de 75 plantas. Para avaliação da severidade da doença e produtividade selecionou-se dez plantas ao acaso previamente demarcadas.

Foram realizadas as adubações de base e cobertura conforme recomendação do Manual de Adubação e Calagem para os estados de Rio Grande do Sul e Santa Catarina (20). A adubação de base foi realizada diretamente no sulco no momento da semeadura e a adubação de cobertura foi realizada a lanço nas linhas.

O controle de plantas daninhas, bem como o controle de pragas foi realizado manualmente e quando necessário com a aplicação de herbicidas e inseticidas registrados para a cultura, com auxílio de pulverizador costal manual, marca Jacto PJH com capacidade de 20 litros.

Os dados meteorológicos da temperatura do ar e precipitação pluvial foram obtidos na estação meteorológica da Estação Experimental de Ituporanga.

\section{Avaliação da cercosporiose}

Semanalmente, após a semeadura, foi avaliado a severidade da cercosporiose nas plantas demarcadas, com auxílio de escala diagramática proposta por May de Mio et al. (15) a intervalos regulares de sete dias. A severidade da doença ao longo do ciclo foi integralizada e calculada a área abaixo da curva de progresso da doença (AACPD), através da fórmula: AACPD $=\sum[(y 1+y 2) / 2] *(t 2-t 1)$, onde $y 1$ e $y 2$ refere-se a duas avaliações sucessivas da intensidade da doença realizadas nos tempos $t 1$ e $t 2$, respectivamente. Avaliou-se a taxa de infecção proposta por Vanderplank (22).

\section{Análise dos Dados}

observados ao longo do tempo caracterizam um estudo longitudinal. Para este, a análise de variância clássica leva à violação da independência entre as observações. Por outro lado, os modelos não lineares de efeitos mistos permitem explorar e modelar adequadamente a variabilidade de dados com erros aleatórios, coletados ao longo do tempo e, possivelmente, com algum nível de correlação entre si. Deste modo, modelos não lineares mistos foram usados para avaliar o progresso da cercosporiose da beterraba no tempo em cada um dos tratamentos.

Após examinar as curvas de tendência em cada tratamento, foi escolhido o modelo de Gompertz como o adequado para representar a severidade acumulada da cercosporiose da beterraba em termos de semanas após o transplante. Para os valores observados foi ajustado um modelo de Gompertz, definido por

$$
y_{i j}=a \times \exp ^{\left(-b \times c^{x i}\right)}
$$

onde, $\mathrm{y}_{\mathrm{ij}}$ representa a severidade (\%) na semana após o transplante para o tratamento $\mathrm{j}, \mathrm{x}_{\mathrm{i}}$ é número de semanas após o transplante, o parâmetro $a$ representa a assíntota superior, $b$ o ponto de inflexão e $c$ é o parâmetro que indica a taxa de progresso. Os parâmetros estimados no modelo de efeitos fixos foram utilizados posteriormente para o ajuste do modelo misto não linear (5).

No caso do modelo misto não-linear, o modelo de Gompertz foi re-definido de acordo com a seguinte fórmula

$$
y_{i j}=\left(a+u_{a j}\right) \times \exp ^{(-b \times c x i)}+e_{i j}
$$


onde, $\mathrm{u}_{\mathrm{aj}}$ representa o efeito aleatório adicionado à assimptota para a representação individual de cada tratamento, enquanto $\mathrm{e}_{\mathrm{ij}}$ representa o erro experimental.

A comparação de diferentes modelos com as combinações possíveis entre os efeitos fixos ( $a, b$ e c) e os aleatórios $\left(u_{a j}, u_{b j}\right.$ e $\left.u_{c j}\right)$ permitiu selecionar a adição de um único efeito aleatório para a assíntota do modelo não linear misto. O melhor ajuste foi obtido com o modelo representado pela equação 2 . Os critérios utilizados para a seleção deste modelo foram o logaritmo da máxima verossimilhança (logLik), o critério de informação de Akaike (AIC), o critério de informação Bayesiano (BIC) e do desvio. Os critérios descritos são usados para comparar o grau de ajuste entre os modelos, sendo o melhor modelo aquele que apresentar os menores valores (19).

Uma vez que os valores iniciais foram encontrados, utilizou-se o software R versão 2.15.1 (17) para ajustes. O modelo misto não-linear foi ajustado com o procedimento nlmer, incluído no pacote lme4 (3), usando o método conhecido como aproximação de Laplace e para visualização foi usado o pacote lattice (5).

A colheita das plantas demarcadas foi realizada 84 e 82 dias após a semeadura, para a primeira e segunda data de semeadura, respectivamente, quando foram pesadas e posteriormente convertidas para produtividade, em Kilogramas por hectare $\left(\mathrm{Kg}_{\mathrm{h}} \mathrm{ha}^{-1}\right)$.

As médias obtidas da AACPD, taxa de infecção $(r)$, severidade final $(\%)$ e produtividade $\left(\mathrm{Kg}\right.$. ha $\left.{ }^{-1}\right)$ foram submetidas à análise de variância pelo teste de $\mathrm{F}$ a $5 \%$, e se significativos, as médias foram comparadas estatisticamente pelo teste de Tukey ao nível de 5\%, usando-se o software estatístico SASM-Agri (4).

\section{RESULTADOS E DISCUSSÃO}

As condições climáticas ocorridas durante a condução dos experimentos propiciaram o desenvolvimento da cercosporiose. A temperatura média do ar ocorrida durante o período de condução dos experimentos, tanto da $1^{\mathrm{a}}$ quanto da $2^{\mathrm{a}}$ época de semeadura, foi próximo aos $22^{\circ} \mathrm{C}$ (Tabela 1), condição esta favorável ao desenvolvimento da doença (8). As Chuvas foram bem distribuídas ao longo das semanas, o que deve ter contribuído, juntamente com a temperatura para o progresso da doença (Tabela 1). A influência da chuva foi também relacionada à cercosporiose em beterraba açucareira na Lituânia (2). Porém, isso é bastante variável, conforme a condição climática de cada ano, pois já foram constatadas diferenças significativas no progresso da cercosporiose em beterraba açucareira (10).

Na primeira época de semeadura, a doença foi constatada na $4^{\text {a }}$ semana após a semeadura e a severidade máxima observada foi de $18 \%$ na média dos genótipos avaliados (Figura 1A), sabendo-se que o máximo observado em campo é $23,61 \%$ de severidade (15). A estabilização da severidade observada a partir da $5^{\mathrm{a}}$ semana após inicio dos sintomas foi decorrente da senescência de folhas atacadas pela doença, que diminuiu o número de folhas avaliadas.

Na segunda época de semeadura, a doença iniciou na quinta semana após a semeadura, uma semana a mais que na primeira época. Como a quantidade de esporos presente no ar está diretamente relacionada inicio e aumento da severidade da cercosporiose (13) e o experimento da segunda época de semeadura foi implantado à três metros do primeiro (primeira época de semeadura), esperava-se maior pressão de inóculo do patógeno e que a epidemia começasse antes e consequentemente maior severidade na segunda época, porém a severidade foi igual. Esse fato possivelmente é devido à precipitação pluvial ocorrida na semana
Tabela 1. Temperatura média e precipitação pluvial acumulada $(\mathrm{mm}) \mathrm{em}$ semanas após a semeadura, registrada entre os dias 31/10/2012 a 20/02/2013, referente ao período experimental da semeadura na primeira época até a colheita da segunda época de semeadura, em Ituporanga, SC. EPAGRI, E.E. Ituporanga, $2012 / 2013$

\begin{tabular}{ccc}
\hline Semana & Temperatura média $\left({ }^{\circ} \mathbf{C}\right)$ & Precipitação pluvial (mm) \\
\hline 1 & 20,7 & 14,6 \\
2 & 20,9 & 15,6 \\
3 & 19,9 & 16,6 \\
4 & 20,7 & 32,7 \\
5 & 22,5 & 47,4 \\
6 & 23,9 & 16,1 \\
7 & 24,0 & 21,0 \\
8 & 23,7 & 32,8 \\
9 & 22,2 & 61,0 \\
10 & 20,9 & 22,0 \\
11 & 21,4 & 82,7 \\
\hline
\end{tabular}

(61 mm) tenha dificultado a liberação e disseminação dos esporos. Isso aconteceu também na beterraba açucareira, pois em período de chuva o inicio da doença foi retardado (10). Da primeira a quinta semana (Figura 1B) após o inicio dos sintomas a severidade máxima atingiu o valor de $18 \%$, semelhante ao apresentado pela primeira época (Figura 1A).

Em decorrência do inicio da doença (Figura 1A e 1B), os experimentos se diferenciaram entre as épocas de semeadura, já que não houve sobreposição longitudinal do desvio da assíntota (asym) (Figura 2). No entanto, ao comparar o intervalo da assíntota (asym) sobre o efeito dos genótipos nas duas épocas de semeadura não se observou diferenças de severidade entre os genótipos testados, já que os desvios se sobrepuseram (Figura 2). Para confirmar a assíntota em ambas as épocas de semeadura a taxa de infecção (Tabela 2) não foi significativa ( $\mathrm{P}<0,05 \%)$ entre os genótipos. Kaiser et al. (13) avaliando o progresso da cercosporiose em diferentes genótipos de beterraba açucareira, constataram que na presença da doença os genótipos se comportaram de maneira semelhante.

Os genótipos avaliados não se diferenciaram quanto a AACPD nos dois períodos de semeadura após sucessão de cebola nas condições de primavera/verão (Tabela 2). No plantio de 31 de outubro constatou-se

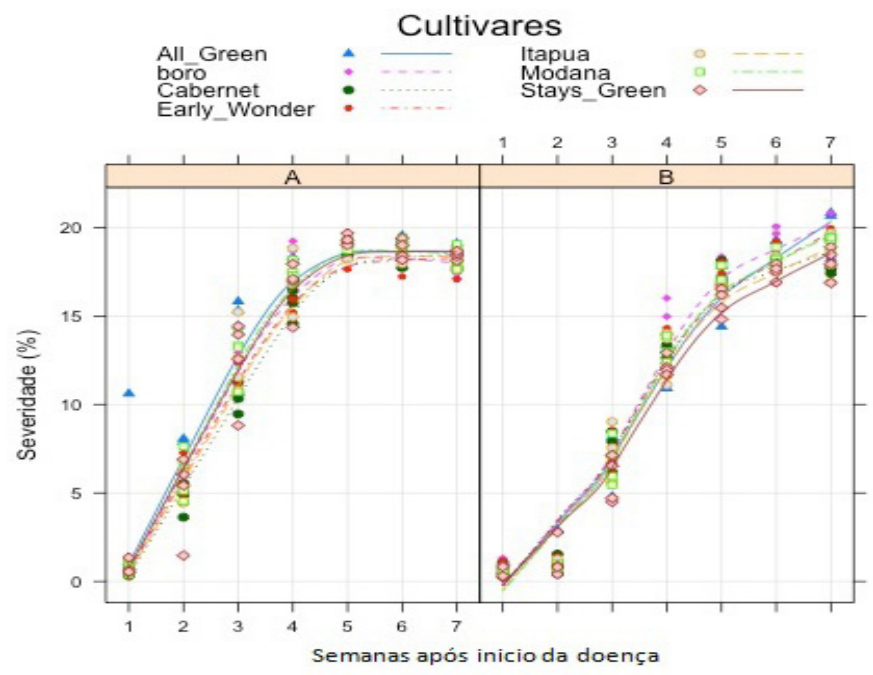

Figura 1. Inicio do progresso da severidade da cercosporiose em diferentes genótipos de beterraba na primeira época (A) (31/10/2012 a 24/01/2013) e segunda época (B) (30/11/2012 a 20/02/2013) de cultivo. EPAGRI, E.E. Ituporanga, 2012/2013. 


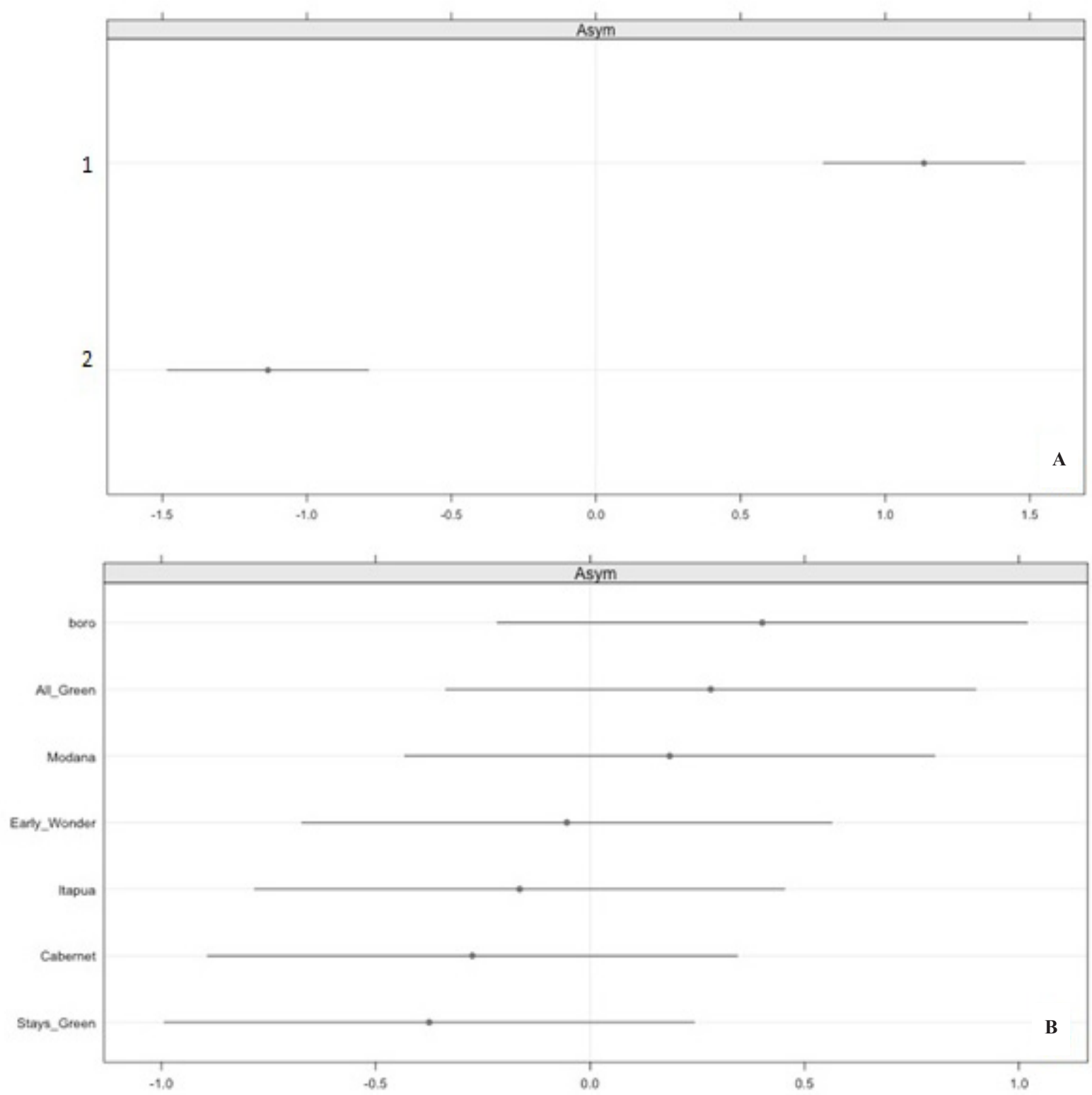

Figura 2. Diferenças na assíntota (asym) dos dados de severidade da cercosporiose da beterraba na primeira (1) e segunda (2) época de semeadura na primavera (A) em diferentes genótipos (B). EPAGRI, E.E. Ituporanga, 2012/2013. EPAGRI, E.E. Ituporanga, 2012/2013.

Tabela 2. Área abaixo da curva de progresso da doença (AACPD), taxa de infecção $(r)$, severidade final da cercosporiose (\%) e produtividade $\left(K_{\text {g.ha }}{ }^{-1}\right)$ entre genótipos de beterraba em função de duas épocas de semeadura, realizadas durante a primavera de 2012. EPAGRI, E.E. Ituporanga, 2012/2013.

\begin{tabular}{|c|c|c|c|c|c|c|c|c|}
\hline \multirow[b]{2}{*}{ Genótipos } & \multicolumn{4}{|c|}{$1^{a}$ época de semeadura $(31 / 10 / 2012)$} & \multicolumn{4}{|c|}{$2^{a}$ época de semeadura (30/11/2012) } \\
\hline & AACPD & $r$ & $\begin{array}{c}\text { Severidade final } \\
(\%)\end{array}$ & $\begin{array}{c}\text { Produtividade } \\
\left(\mathrm{Kg} \mathrm{ha}^{-1}\right)\end{array}$ & AACPD & $r$ & $\begin{array}{c}\text { Severidade final } \\
(\%)\end{array}$ & $\begin{array}{c}\text { Produtividade } \\
\left(\mathrm{Kg} \mathrm{ha}^{-1}\right)\end{array}$ \\
\hline Boro & $585,64 \mathrm{~ns}$ & $0,06 \mathrm{~ns}$ & $17,79 \mathrm{~ns}$ & $15.75 \mathrm{~ns}$ & $489,81 \mathrm{a}$ & $0,06 \mathrm{~ns}$ & $19,73 \mathrm{a}$ & $12.65 \mathrm{~ns}$ \\
\hline Modana & 589,50 & 0,08 & 18,25 & 23.83 & $464,21 \mathrm{a}$ & 0,08 & $19,23 \mathrm{a}$ & 16.19 \\
\hline All Green & 604,02 & 0,78 & 18,46 & 19.45 & $466,05 \mathrm{a}$ & 0,09 & $19,84 \mathrm{a}$ & 16.55 \\
\hline Early Wonder & 564,31 & 0,07 & 17,99 & 20.25 & $471,73 \mathrm{a}$ & 0,07 & $19,42 \mathrm{a}$ & 15.05 \\
\hline Itapuã & 573,66 & 0,08 & 18,16 & 32.62 & $452,75 \mathrm{a}$ & 0,08 & $18,42 \mathrm{a}$ & 10.89 \\
\hline CV (\%) & 5,39 & 10,42 & 2,90 & 39,38 & 4,32 & 11,16 & 4,42 & 34,05 \\
\hline
\end{tabular}

Médias seguidas pela mesma letra não diferem significativamente entre si, teste de Tukey em nível de 5\% de significância; ns: não significativo pelo teste F 5\%. 
que a AACPD não diferiu entre os genótipos avaliados, enquanto que no segundo período de semeadura foi significativa, no entanto não diferiu estatisticamente. No híbrido Cabernet foi detectada uma redução de 10,62\% no índice de AACPD quando comparado com All Green (Tabela 1). No plantio de 30 de novembro, o híbrido Boro teve redução de $11,45 \%$ no valor de AACPD em comparação com Stays Green, a variedade mais plantada na região.

Os valores de severidade final (Tabela 2) não apresentaram diferenças significativas $(\mathrm{P}<0,05)$ na primeira e segunda época de semeadura entre os genótipos. Em outros trabalhos realizados com beterraba açucareira (10) demonstraram que o genótipo suscetível apresentou uma severidade máxima de $15,62 \%$ enquanto para o genótipo suscetibilidade foi 5,66\% em cinco anos de avaliação. Bălău (2) constatou pequenas diferenças, entre 2,0 e 2,4 pontos percentuais na severidade máxima de três genótipos, semelhante aos resultados aqui apresentados.

A produtividade $\left(\mathrm{Kg}_{\left.\mathrm{g} \cdot \mathrm{ha}^{-1}\right)}\right.$ não diferiu entre os genótipos avaliados na primeira e segunda época de semeadura (Tabela 2). Na Lituânia, também não encontraram diferenças significativas $(\mathrm{P}<0,05 \%)$ para produtividade de beterraba açucareira afetada por cercosporiose (10). Também Bălău (2) na Romênia também não verificou diferença de produtividade entre genótipos em diferentes anos de avaliação com a presença da doença. Embora não significativo, a cultivar mais produtiva Itapuã, no primeiro experimento, teve uma diferença de 66 $\%$ na produtividade em relação ao segundo (Tabela 2). Enquanto que o menos produtivo, o híbrido Boro, no primeiro ensaio, constatou-se a diferença de apenas $20 \%$ em relação ao segundo ensaio (Tabela 2).

Verificou-se que não houve diferenças significativas no progresso de epidemia da cercosporiose da beterraba entre os genótipos e em função das épocas de semeadura na primavera nas condições do Alto Vale do Itajaí, SC.

\section{AGRADECIMENTOS}

Ao CNPq e à FAPESC (chamada pública do acordo de cooperação $\mathrm{CNPq}+\mathrm{FAPESC}$ - Repensa) pelo apoio financeiro recebido para condução deste trabalho e pela concessão de bolsas ATP - B.

\section{REFERÊNCIAS BIBLIOGRÁFICAS}

1. AGROFIT. Sistema de agrotóxicos fitossanitários. Disponível em: $<$ http:// agrofit.agricultura.gov.br/agrofit_cons/principal_agrofit_cons $>$. Acesso em: 24 abr. 2013.

2. Bălău, A.M. Research regarding the epidemic evolution of Cercospora leaf spot (Cercospora beticola Sacc.) under ezareni farm conditions. Lucrăriștiințifice, v.54, n.2, p.199-202, 2011.

3. Bates, D.; Maechler, M.; Bolker, B. lme4: Linear mixed-effects models using S4 classes. R package version ISBN 0.999375-42, 2011. Disponível em: $<$ http://www.R-project.org>. Acesso em: 15 fev. 2013.

4. Canteri, M.G.; Althaus, R.A.; Virgens Filho, J.S.; Giglioti, E.A.; Godoy, C.V.
SASM - Agri: Sistema para análise e separação de médias em experimentos agrícolas pelos métodos Scoft - Knott, Tukey e Duncan. Revista Brasileira de Agrocomputação, Ponta Grossa, v.1, p.18-24, 2001.

5. Davidian, M.; Giltinan, D.M. Nonlinear Models for Repeated Measurement Data: An Overview and Update, Jabes, v.8, p.387-419, 2003.

6. Deepayan, S. Lattice: Multivariate Data Visualization with R. New York: Springer, 2008. Disponível em: <http://www.R-project.org>. Acesso em: 15 fev. 2013.

7. EMBRAPA. Empresa Brasileira de Pesquisa Agropecuária. Sistema Brasileiro de classificação de solos. Brasília: Embrapa. 1999. 412p.

8. Ferreira, M.D.; Tivelli, S.W. Cultura da beterraba: recomendações gerais. Guaxupé, Cooxupé, 1989, 14p. (Boletim Técnico, 2).

9. Filgueira, F.A.R. Novo manual de olericultura: agrotecnologia moderna na produção e comercialização de hortaliças. 3. Ed. rev. e ampl. Viçosa: UFV. 2007. 421p.

10. Gaurilčikienè, I.; Deveikytė, I.; Petraitienè, E. Epidemic progress of Cercospora beticola Sacc. in Beta vulgaris L. under different conditions and cultivar resistance. Biologija, v.4, p.54-59, 2006.

11. Hermann, $O$. Reconnaître les maladies foliaires de la betterave au champ. Institut Royal Belgepourl 'Amérlioration de la Betterave (IRBAB/KBIVB), 1998. Disponível em:<http://www.irbab-kbivb.be/.../GuideMaladiesFoliaires.pdf>. Acesso em: 28 mai 2013.

12. Jesus Junior, W.C.; Pozza, E.A.; Vale, F.X.R.; Anguilera, G.M. Análise Temporal de Epidemias. In: Vale, F. X. R.; Jesus Junior, W. C.; Zambolim, L. (Ed.). Epidemiologia aplicada ao manejo de doenças de plantas. Belo Horizonte: Perffil, 2004, cap.4, p.127-191.

13. Kaiser, U.; Kluth, C.; Märländer, A. variety-specific epidemiology of Cercospora beticola Sacc. and consequences for threshold-based timing of fungicide application in sugar beet. Journal of Phytopathology, Berlin, v.158, n.4, p.296-306, 2010.

14. Khan, J.; Q.I., A.; Khan, M.F. Fluctuations in number of Cercospora beticola conidia in relationship to environment and disease severity in sugar beet. Phytopathology, St. Paul, n.7, v.99, p.796-801, 2009.

15. May de Mio, L.L.; Oliveira, R.A.; Floriani, A.M.V.; Schuber, J.M.; Poltronieri, A.S.; Araujo, M.A.; Tratch, R. Proposta de escala diagramática para quantificação da cercosporiose da beterraba. Scientia Agraria, Curitiba, v.9, n.3, p.331-337, 2008.

16. Puiatti, M.; Finger, F.L. Cultura da beterraba. In: FONTES PCR. Olericultura: teoria e prática. Viçosa: Suprema, p.345-354, 2005.

17. R Development Core Team (2012). R: A language and environment for statistical computing. R Foundation for Statistical Computing, Vienna, Austria. Disponível em: <http://www.R-project.org>. Acesso em: 15 fev. 2009.

18. Sakamoto, Y.; Ishiguro, M.; Kitagawa, G. Akaike Information Criterion Statistics. Dordrecht, Holland :Kluwer Academic Publishers, 1986, 256p.

19. Sakamoto, Y.; Ishiguro, M.; Kitagawa, G. Akaike Information Criterion Statistics. Dordrecht, Holland:Kluwer Academic Publishers, 1986, 256p.

20. Sociedade Brasileira de Ciência do Solo. Comissão de Química e Fertilidade do Solo Manual de Adubação e Calagem para os Estados do Rio Grande do Sul e de Santa Catarina. Porto Alegre: Evangraf, 2004, 400p.

21. Tivelli, S.W; Factor, T.L.; Teramoto, J.R.S.; Fahi, E.G.; Moraes, A.R.A.; Trani, P.E.; May, A. Beterraba, do plantio à comercialização. Série Tecnologia APTA. Boletim Técnico IAC, 210. Campinas: Instituto Agronômico. 2011, 45p.

22. Vanderplank, J.E. Plant disease: epidemics ant control. New York: Academic Press, 1963, 349p.

24. Weiland, J.; Koch, G. Sugar beet leaf spot disease (Cercospora beticola Sacc.). Molecular Plant Pathology, London, v.5, n.3, p.157-166, 2004. 